University of Nebraska - Lincoln

DigitalCommons@University of Nebraska - Lincoln

Using Thermally Coupled Reactive Distillation Columns in Biodiesel Production

Nghi Nguyen

University of Nebraska - Lincoln, nghinguyen1985@yahoo.com

Yaşar Demirel

University of Nebraska - Lincoln, ydemirel2@unl.edu

Follow this and additional works at: https://digitalcommons.unl.edu/cbmedemirel

Part of the Chemical Engineering Commons

Nguyen, Nghi and Demirel, Yaşar, "Using Thermally Coupled Reactive Distillation Columns in Biodiesel Production" (2011). Yasar Demirel Publications. 5.

https://digitalcommons.unl.edu/cbmedemirel/5

This Article is brought to you for free and open access by the Chemical and Biomolecular Research Papers -- Faculty Authors Series at DigitalCommons@University of Nebraska - Lincoln. It has been accepted for inclusion in Yasar Demirel Publications by an authorized administrator of DigitalCommons@University of Nebraska - Lincoln. 
Published in Energy: The International Journal (2011) 36: 4,838-4,847. http://www.elsevier.com/locate/energy0360-5442. DOI: 10.1016/j.energy.2011.05.020. Copyright 2011, Elsevier. Used by permission.

Article history: Received December 29, 2010; received in revised form May 10, 2011; accepted May 15, 2011; authors' version uploaded to the University of Nebraska-Lincoln Digital Commons May 30, 2012

\title{
Using Thermally Coupled Reactive Distillation Columns in Biodiesel Production
}

\author{
Nghi Nguyen*, Yaşar Demirel \\ Department of Chemical and Biomolecular Engineering, University of Nebraska-Lincoln, Lincoln, Nebraska, U.S.A. \\ *Corresponding author: nghinguyen1985@yahoo.com. Demirel: ydemirel2@unl.edu.
}

Keywords: Biodiesel plant, Esterification, Simulation, Thermally-coupled distillation, Reactive distillation, Thermodynamic analysis

\begin{abstract}
Production of ethyl dodecanoate (biodiesel) using lauric acid and methanol with a solid acid catalyst of sulfated zirconia is studied by using two distillation sequences. In the first sequence, the methanol recovery column follows the reactive distillation column. In the second sequence, the reactive distillation and methanol recovery columns are thermally coupled. Thermally coupled distillation sequences may consume less energy by allowing interconnecting vapor and liquid streams between the two columns to elminate reboiler or condenser or both. Here we study the thermally coupled side-stripper reactive distillation and eliminate the condenser of the reactive distillation column. Both the sequences are optimized by using the thermal and hydraulic analyses of the Column Targeting Tools of Aspen Plus simulator. Comparisons of the optimized sequences show that in the thermally coupled sequence, the energy consumption is reduced by $13.1 \%$ in the reactive distillation column and $50.0 \%$ in the methanol recovery column. The total exergy losses for the columns are reduced by $281.35 \mathrm{~kW}$ corresponding to $21.7 \%$ available energy saving in the thermally coupled sequence. In addition, the composition profiles indicate that the thermally coupled reactive distillation column operates with the lower concentration of water in the reaction zone which reduces catalytic deactivation.
\end{abstract}

\section{Introduction}

Separation by distillation is an energy-intensive process and consumes approximately $3 \%$ of the energy in the world [1]. TA (Thermodynamic analysis), process intensification, and process heat integration are some of the ways for retrofitting [2,3]. TA through CGCC (column grand composite curves) generated by the thermal analysis of Column Targeting Tools of Aspen Plus simulator identifies scopes for modification in feed location, reflux ratio, feed conditioning, and side condensing and reboiling to reduce wasted energy due to heat and mass transfer, mixing, and pressure drop [4-8]. Aspen Plus version V7.2 is used for this simulation. In a reactive distillation column, the scope of thermal analysis is limited, such as the feed locations are constrained to maximize the conversion. Effects of molar reflux ratio and side reboiling on conversion and exergy profiles on BCRD (base case reactive distillation) column were previously investigated [7]. The results show that there is a tradeoff between energy saving and conversion; reduction in reflux ratio and addition of a side reboiler may reduce exergy losses; however, the conversion may also decrease.

RD (Reactive distillation) consists of separation and reaction zones, which may minimize operational and equipment costs by decreasing waste energy and overcoming thermodynamic and chemical equilibrium limitations [9-13]. However, usage of RD requires reaction temperature to occur within separation temperature range, suitable relative volatilities of the components and reasonably fast reaction rate preferably in liquid-phase due to low residence time in vapor phase [14]. Further reduction of energy and equipment cost is possible by thermally coupled distillation sequences [15-22] as they allow interconnecting vapor and liquid flows between the two columns to eliminate the reboiler or condenser or both [23]. Thermally-coupled side-rectifier, sidestripper, and Petlyuk columns are the three well-known configurations. Petlyuk configuration is restricted due to bidirectional vapor and liquid flows $[24,25]$. The side-rectifier and side-stripper configurations tend to be the most efficient ones [19].

Ethyl acetate production with thermally-coupled reactive distillation using ethanol and acetic acid was previously investigated by Barroso-Muñozetal [26]. Their Petlyuk column needs larger number of stages and hence results in higher capital investment [5-7]. Also, the overall conversion is low, which may lead to higher cost for the separation. Recently, Gomez-Castro et al. [22] proposed a biodiesel production process that employed supercritical methanol method using reactive Petlyuk column. However, excessive operating pressure requirement may result in higher equipment and operating costs.

This study considers TCRD (thermally-coupled reactive distillation) configuration to produce ester using lauric acid 

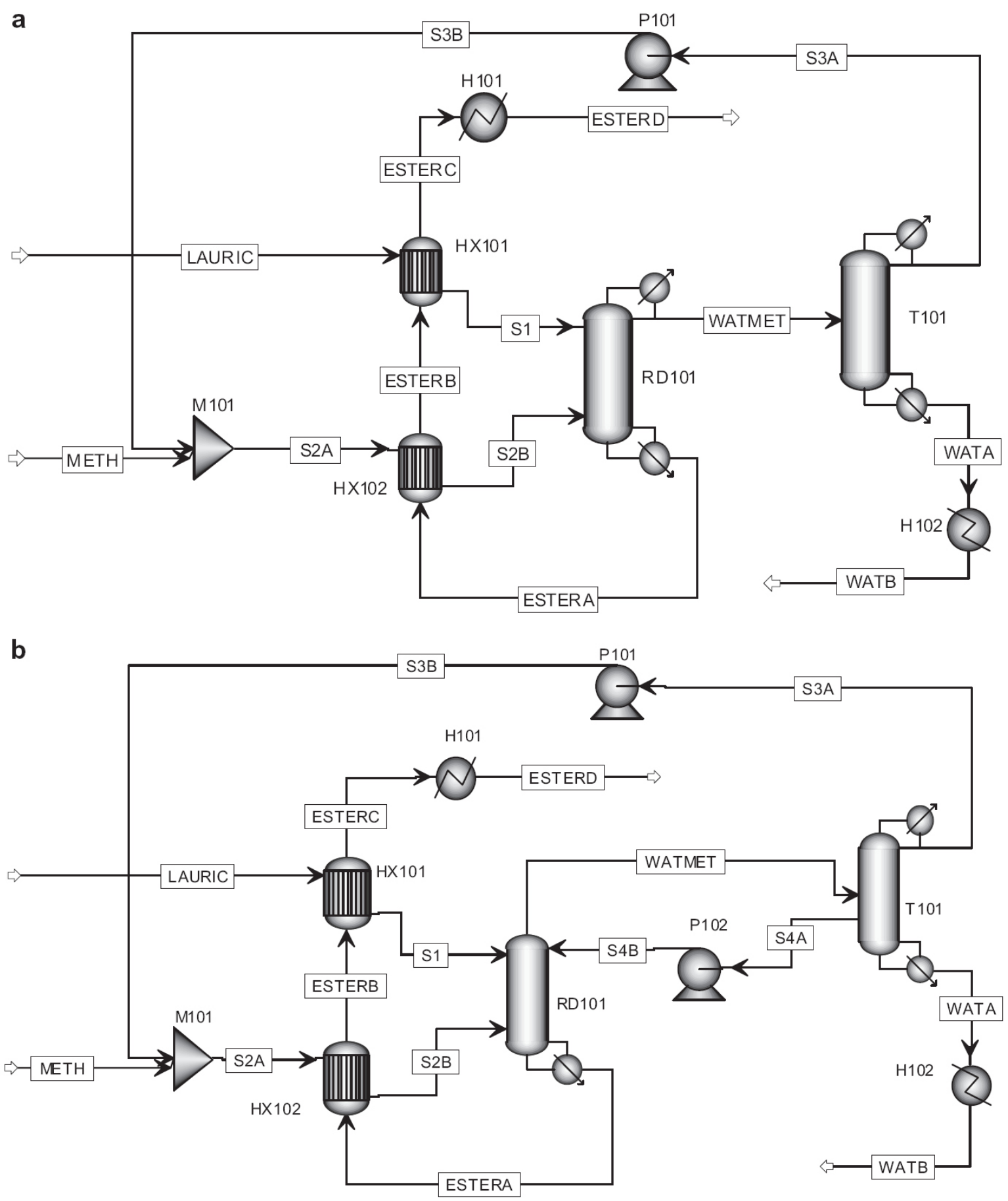

Figure 1. Process flow diagrams for biodiesel plant: (a) base case design; (b) thermally-coupled design.

and methanol with a solid acid catalyst of sulfated zirconia $\left(\mathrm{SO}_{4}^{-2} / \mathrm{ZrO}_{2}\right)$ [27-29]. In this proposed biodiesel plant, TCSRD (thermally-coupled side-stripper reactive distillation) configuration has been considered, since using the reactive distillation column as a side-rectifier may cause lower reaction rate because the reaction zone temperature must be within the separation temperature of methanol and water. Also, using the methanol recovery column as a rectifier may disrupt the reaction zone with the side feed and withdraw [10-12,15-19].
2. TA (Thermodynamic Analysis)

TA determines the net enthalpy deficits and exergy losses due to irreversibility at each stage of a column to identify the scope and extent of retrofits or improvements by reducing the irreversibility and/or distributing them evenly [30-33]. The Column Targeting Tools of Aspen Plus performs thermal analysis and hydraulic analyses. Thermal analysis produces the CGCC (column grand composite curves) and the exergy loss profiles for rigorous column calculations based on 
the PNMTC (Practical Near-Minimum Thermodynamic Condition). These profiles represent the cumulative heating and cooling requirements for the column to operate at PNMTC. This approximation takes into account the inefficiencies introduced through pressure drops, mixing, and heat and mass transfer.

\subsection{CGCC (Column Grand Composite Curve)}

The CGCC displays the net enthalpies for the actual and ideal operations at each stage, and theoretical minimum cooling and heating requirements in the temperature range of separation. The CGCCs are available as stage-enthalpy (Stage-H) and T-H (temperature eenthalpy) profiles and help in identifying the following scopes: (i) feed location (appropriate placement), (ii) reflux ratio (reflux ratio vs. number of stages), (iii) feed conditioning (heating or cooling), and (iv) side condensing and reboiling. The area between the actual and the ideal operations in a CGCC should be small. A sharp enthalpy change occurring on the condenser side indicates that a feed has been introduced too high up in the column and should be moved down. Similarly, a feed introduced too low in the column will cause a sharp enthalpy change on the reboiler side and should be moved up. Appropriate feed placement removes the distortions on the CGCC and may reduce the condenser or reboiler duty. Reflux ratio reduction lowers the condenser and reboiler duties and decreases operating costs. However, it will increase the number of stages and increase capital costs to preserve the separation. User must carefully analyze to determine whether savings in operating costs compensate higher capital costs. Feed preheating or cooling can reduce thermal loss on the feed stage. Using heat sources available in the plant are desirable and side condensing and side reboiling provide the column with a cheaper cold or hot utility [34,35].

Using the equilibrium compositions of light (L) and heavy (H) key components minimum vapor and liquid flow rates leaving the same stage with the same temperatures can be estimated from the following mass balances $[4,5]$

$$
\begin{aligned}
& \dot{V}_{\min }=\frac{1}{y_{L}^{*}}\left(\dot{D}_{L}+\dot{L}_{\min } x_{L}^{*}\right) \\
& \dot{L}_{\min }=\frac{1}{x_{H}^{*}}\left(\dot{V}_{L} y_{H}^{*}-\dot{D}_{H}\right)
\end{aligned}
$$

The enthalpies for the minimum vapor and liquid flows are obtained from the molar flow ratios

$$
\begin{aligned}
& H_{V \min }=H_{V}^{*}\left(\frac{\dot{V}_{\min }}{\dot{V}^{*}}\right) \\
& H_{L \min }=H_{L}^{*}\left(\frac{\dot{L}_{\min }}{\dot{L}^{*}}\right)
\end{aligned}
$$

where $\dot{V}^{*}$ and $\dot{L}_{*}$ are the molar flows of equilibrium, and $H_{V}^{*}$ and $H_{L}^{*}$ are enthalpies of equilibrium vapor and liquid streams leaving the same stage, respectively. From the enthalpy balances at each stage, the net enthalpy deficits are calculated by

$H_{\text {def }}=H_{\text {Lmin }}-H_{\mathrm{Vmin}}+H_{\mathrm{D}}$ (before the feed stage)

$H_{\text {def }}=H_{\text {Lmin }}-H_{\mathrm{Vmin}}+H_{\mathrm{D}}-H_{\text {feed }}$ (after the feed stage)

After adding the individual stage-enthalpy deficits to the condenser duty, the enthalpy values are cascaded, and plot-

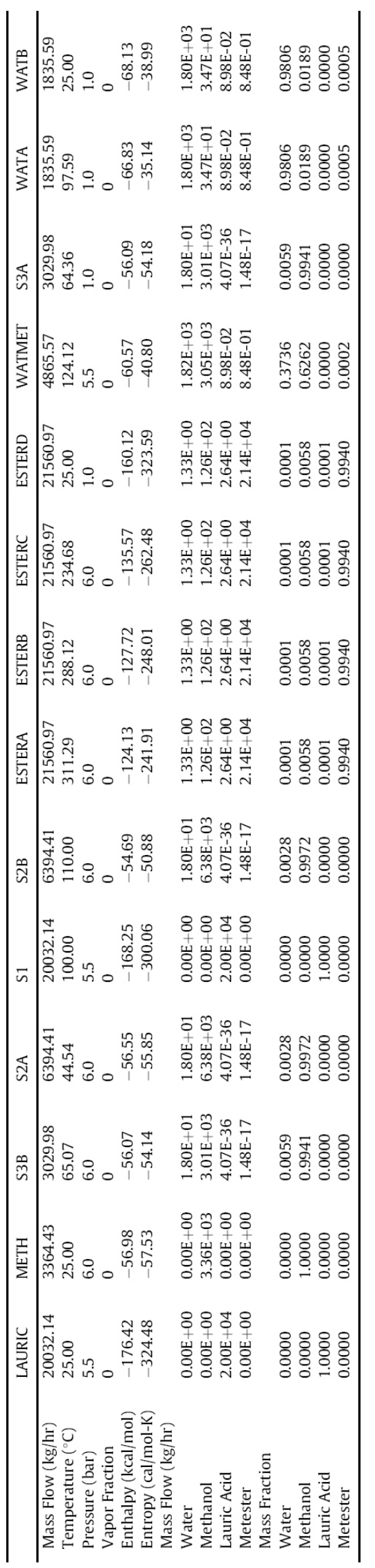




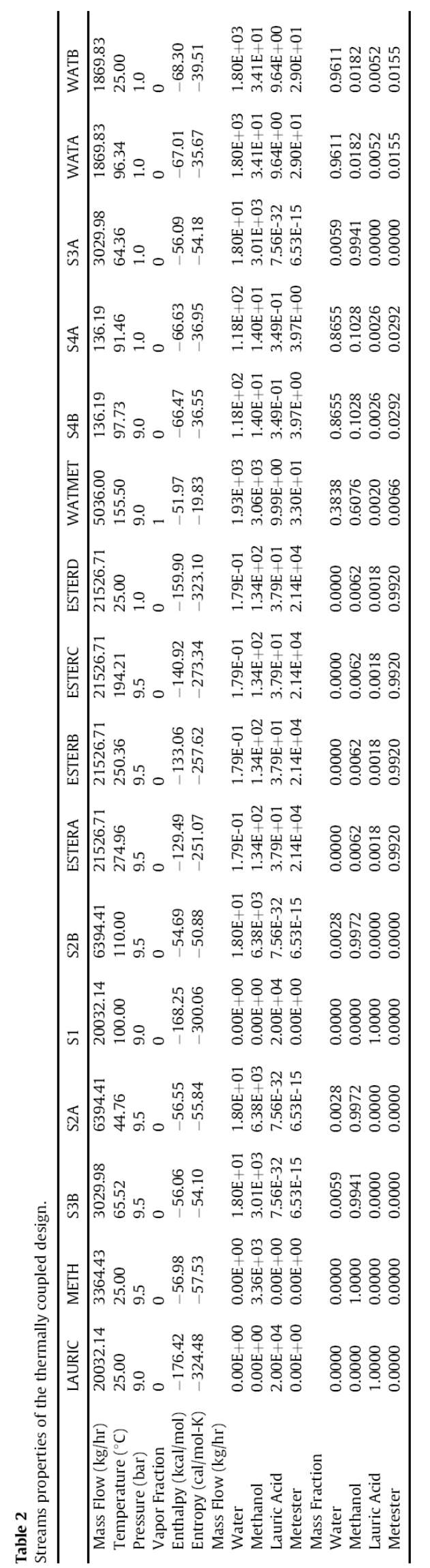

ted in the CGCC. This is called the top-down calculation procedure, which will be the same with the bottom-up calculations for a stage without any feed. At the feed stage, mass and energy balances differ from a stage without feed. For the two procedures to yield similar results, the enthalpy deficit at the feed stage becomes $[4,5]$

$$
\dot{H}_{\mathrm{def}, F}=\dot{Q}_{C}+\dot{D}\left(H_{D}+H_{L} \frac{x_{D}-y_{F}^{*}}{y_{F}^{*}-x_{F}^{*}}-H_{V} \frac{x_{D}-x_{F}^{*}}{y_{F}^{*}-x_{F}^{*}}\right)
$$

The values of $y_{F}^{*}$ and $x_{F}^{*}$ may be obtained from an adiabatic flash for a single phase feed, or from the constant relative volatility estimated with the converged compositions at the feed stage and feed quality. This procedure can be reformulated for multiple feeds and side products as well as for different choices of the key components. For nonideal multicomponent systems pinch may exist in rectifying and stripping sections.

A horizontal distance between the CGCC pinch point and the vertical axis represents the excessive use of heat, and therefore the scope for reduction in reflux ratio [36]. For smaller reflux ratios, the CGCC will move toward the vertical axis, and hence reduce the reboiler and condenser duties, which may be estimated by

$$
\dot{Q}_{R}-\dot{Q}_{R, \text { min }}=\dot{Q}_{C}-\dot{Q}_{C, \min }=\dot{D} \lambda\left(R-\frac{x_{D}-y_{F}^{*}}{y_{F}^{*}-x_{F}^{*}}\right)
$$

where $\lambda$ is the heat of vaporization and $R$ is the reflux ratio $[4,5]$. The horizontal distance of the CGCC from the temperature axis, however, determines the targets for installing a side reboiler or side condenser at suitable temperatures [30]. For example, a sharp change on the reboiler side may be due to subcooled feed, and a feed preheater with a heat duty depending on the change can be installed [37]. On the other hand, a sharp change in the enthalpy represents inappropriate feed conditioning, such as feed quality or temperature. Feed conditioning is usually preferred to side condensing or reboiling, since the side heat exchangers are effective at suitable temperature levels or stages only.

\subsection{Exergy Loss Profiles}

Exergy $\left(E_{x}\right)$ is the accessible work potential and defines the maximum amount of work that may be performed theoretically by bringing a resource into equilibrium with its surrounding through a reversible process. Specific exergy is defined by

$$
e_{x}=\Delta h-T_{\mathrm{o}} \Delta s=\left(h-h_{\mathrm{o}}\right)-T_{\mathrm{o}}\left(s-s_{\mathrm{o}}\right)
$$

where $h$ is the molar enthalpy, $s$ is the molar entropy, and $T_{\mathrm{o}}$ is the reference state temperature. The reference temperature and pressure states are $298.15 \mathrm{~K}$ and $1 \mathrm{~atm}$, respectively. Aspen Plus uses ideal gas heat of formation and ideal gas Gibbs free energy of formation to compute enthalpies, entropies, and Gibbs free energies; these formation energies may be set equal to zero if there is no reaction occurred [38]. Exergy is a function of both the physical properties of a system and its environment. Exergy Loss profiles are available as stage-exergy loss and temperature-exergy loss profiles, and measure their reversibility in the column due to momentum loss (pressure driving force), thermal loss (temperature driving force/mixing), and chemical potential loss (mass transfer driving force/mixing). These profiles can be used to exam- 
Table 3

Comparison of operating conditions and configurations of reactive distillation column RD101 and distillation column T101 of base case and thermally-coupled designs.

$\begin{array}{lcc} & \text { Base Case Design } & \\ \text { Condition \& Configurations } & \text { RD101 } & \text { T101 } \\ \text { Number of stages } & 30 & 12 \\ \text { S1 feed stage } & 3 & - \\ \text { S2B feed stage } & 29 & - \\ \text { S4B feed stage } & - & - \\ \text { WATMET feed stage } & - & 9 \\ \text { S1 temperature, }{ }^{\circ} \mathrm{C} & 100 & - \\ \text { S2B temperature, }{ }^{\circ} \mathrm{C} & 110 & - \\ \text { Molar reflux ratio } & 0.1 & 1.55 \\ \text { S4B flow rate, } \mathrm{kmol} / \mathrm{hr} & - & - \\ \text { Reaction stages } & 3-29 & - \\ \text { Distillate rate, } \mathrm{kmol} / \mathrm{hr} & 196 & 95 \\ \text { Column diameter, } \mathrm{m} & 1.04 & 1.10 \\ \text { Liquid hold up, } \mathrm{cm}{ }^{3} & 0.043 & - \\ \text { Condenser duty, } \mathrm{kW} & -2168.38 & -2375.23 \\ \text { Condenser temperature, }{ }^{\circ} \mathrm{C} & 124.12 & 64.36 \\ \text { Condenser pressure, bar } & 5.5 & 1.0 \\ \text { Side condenser stage } & - & - \\ \text { Side condenser duty, } \mathrm{kW} & - & - \\ \text { Reboiler duty, } \mathrm{kW} & 5634.95 & 2136.23 \\ \text { Boil up rate, kmol/hr } & 177.80 & 186.19 \\ \text { Bottoms rate, } \mathrm{kmol} / \mathrm{hr} & 104 & 101 \\ \text { Reboiler temperature, }{ }^{\circ} \mathrm{C} & 311.29 & - \\ \text { Reboiler pressure, bar } & 6.0 & 108.36 \\ \text { Total Conversion, } \mathrm{mol} \% & 99.99 & \\ \text { Exergy loss, } \mathrm{kW} & 1189.04 & \end{array}$

ine the degradation of accessible work for the column. Higher value of exergy loss means more thermodynamic imperfection, consequently, higher energy consumption to achieve a desirable separation. For a steady state system, the exergy balance is not conserved [39]

$$
\begin{aligned}
\dot{E}_{x, \text { loss }}= & \sum_{\text {in }}\left[\dot{n} e_{x}+\dot{Q}\left(1-\frac{T_{0}}{T_{s}}\right)+\dot{W}_{s}\right] \\
& -\sum_{\text {out }}\left[\dot{n} e_{x}+\dot{Q}\left(1-\frac{T_{0}}{T_{s}}\right)+\dot{W}_{s}\right]
\end{aligned}
$$
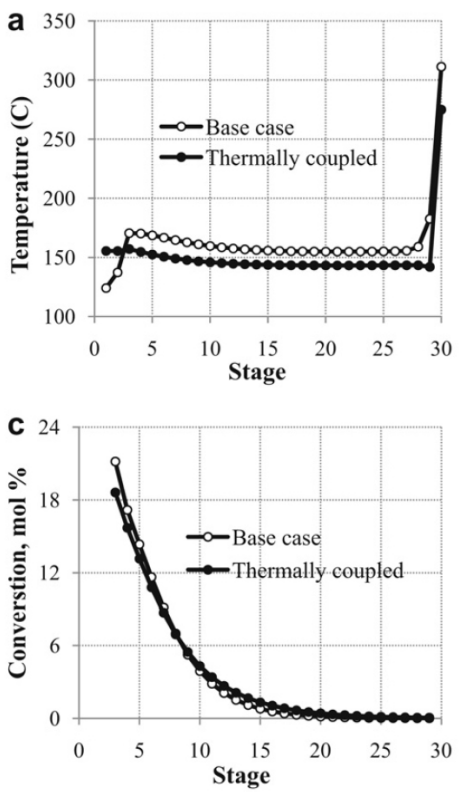

Thermally Coupled Design

$\begin{array}{cccc}\text { Total } & \text { RD101 } & \text { T101 } & \text { Total } \\ & 30 & 12 & \\ & 3 & - & \\ & 29 & - & \\ & 1 & - & \\ & - & - & \\ & 100 & - & \\ & 110 & 2.02 & \\ & - & - & \\ & 7 & - & \\ & 3-29 & 10 & \\ & 203 & -2809.62 \\ & 0.86 & -2809.62 & \\ -4543.61 & 0.043 & 64.36 & -600.00 \\ & 0.00 & 1.0 & 5966.35 \\ & 155.50 & 6 & \\ & 9.0 & -600.00 & \\ & - & 1067.38 & \\ 7771.18 & 4898.97 & 89.63 & \\ & 217.53 & 101 & \\ & 104 & 96.34 & \\ & 274.96 & 1.0 & \\ & 9.5 & 108.743217 & \\ 1297.40 & 99.76 & & \end{array}$

where $\dot{W}_{s}$ and $\dot{E}_{x, l o s}$ are the shaft work and exergy losses, respectively.

For distillation columns, the minimum exergy flow rate required for separation is directly proportional to the differences between the exergy of the product and feed streams

$$
\dot{E}_{x, \min }=\sum_{\text {out }} \dot{n} e_{x}-\sum_{\text {in }} \dot{n} e_{x}
$$
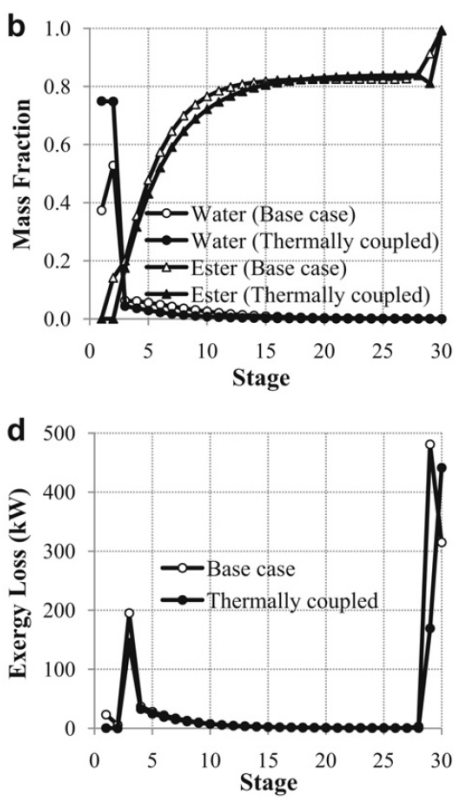

Figure 2. Comparison of operating conditions for reactive distillation column RD101: (a) temperature profiles; (b) composition profiles; (c) reaction profiles; (d) exergy loss profiles. 
a

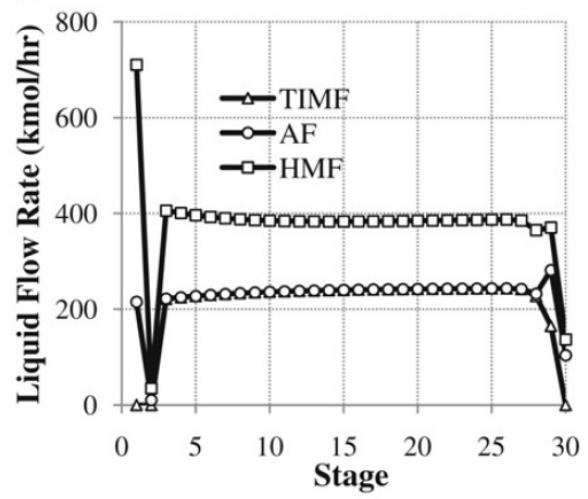

C

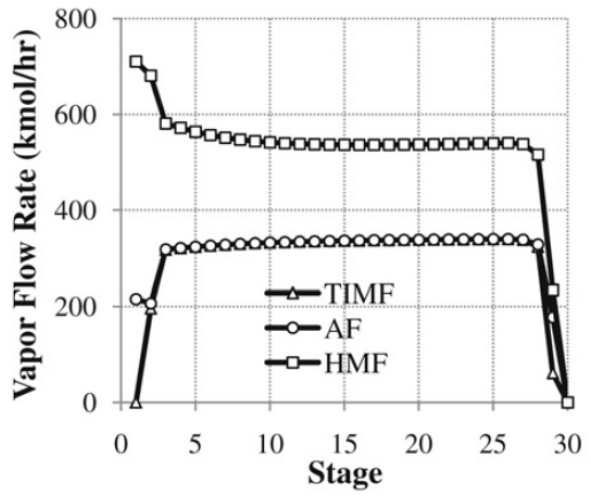

e

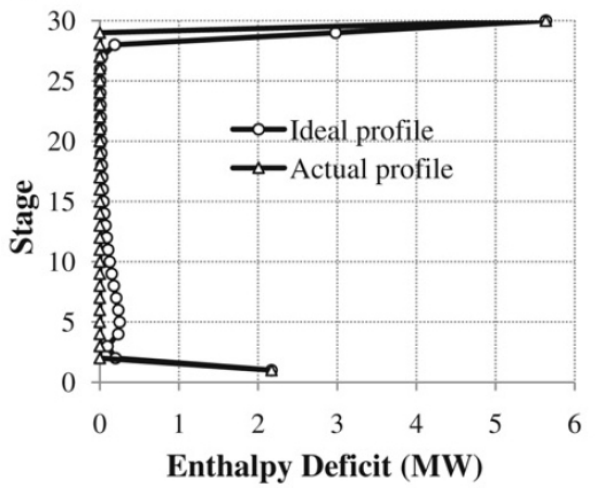

b

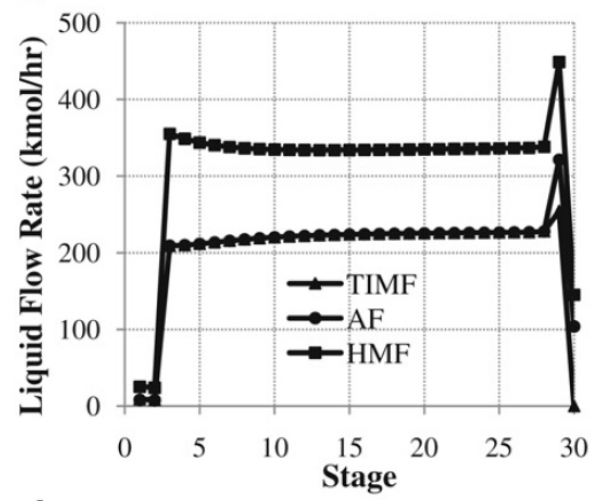

d

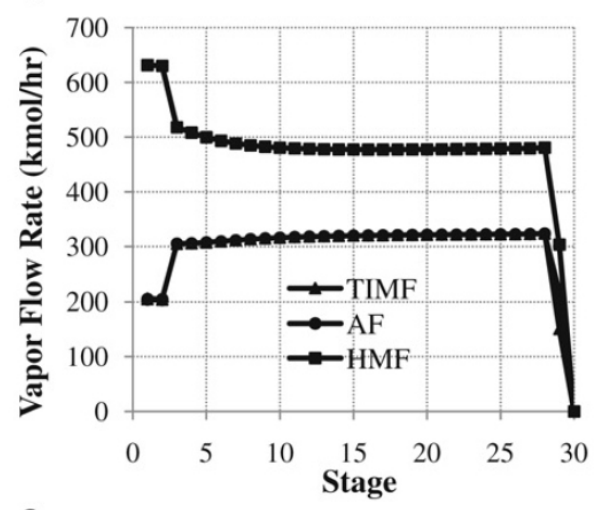

f

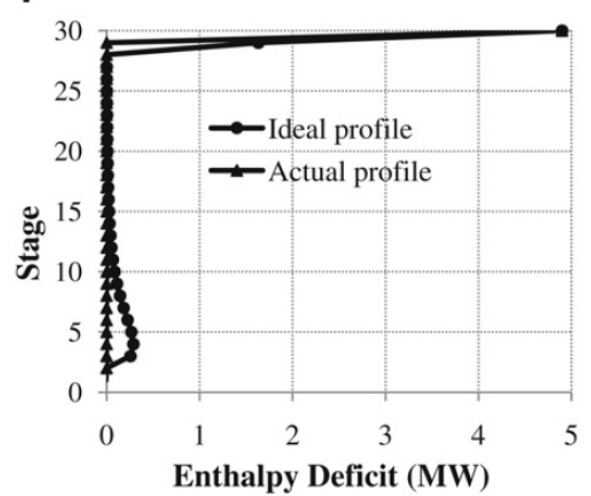

Figure 3. Hydraulic analysis and enthalpy deficit profiles for column RD101: (a) stage-liquid flow rate profiles of base case design; (b) stage-liquid flow rate profiles of thermally-coupled design; (c) stage-vapor flow rate profiles of base case design; (d) stage-vapor flow rate profiles of the thermally-coupled design; (e) stage-enthalpy deficit curves of base case design; (f) stage-enthalpy deficit curves of the thermally-coupled design.

The sign of $\dot{E}_{x, \min }$ depends on the energy stored in the inlet and outlet streams.

Thermodynamic efficiency $(\eta)$ is the ratio between the total useful work output and the total exergy input. When $\dot{E}_{x, \min }$ is greater than zero, the $\eta$ is calculated by References [4,5]

$$
\eta=\frac{\dot{E}_{x, \min }}{\dot{E}_{x, \min }+\dot{E}_{x, \text { loss }}}
$$

If the value of $\dot{E}_{x, \min }$ is negative, the $\eta$ is given by

$$
\eta=\frac{\dot{E}_{x, \text { min }}}{\dot{E}_{x, \min }-\dot{E}_{x, \text { loss }}}
$$

Exergy loss is always greater than zero in every irreversible processes, hence, $\eta$ must lie between 0 and 1 . A conventional distillation column receives heat in the reboiler, performs the separation work, and releases the rest of the amount in the condenser. Thus, it resembles a thermal engine and the efficiency is typically much less than 1 .

\section{Reactive Distillation}

Reactive distillation column RD101 shown in Figure 1a and b has 30 stages, rectifying section located at the top, reaction zone located at the middle, and stripping section located at the bottom of the column. The column operates with a total condenser and a kettle reboiler. The activity coefficient model 

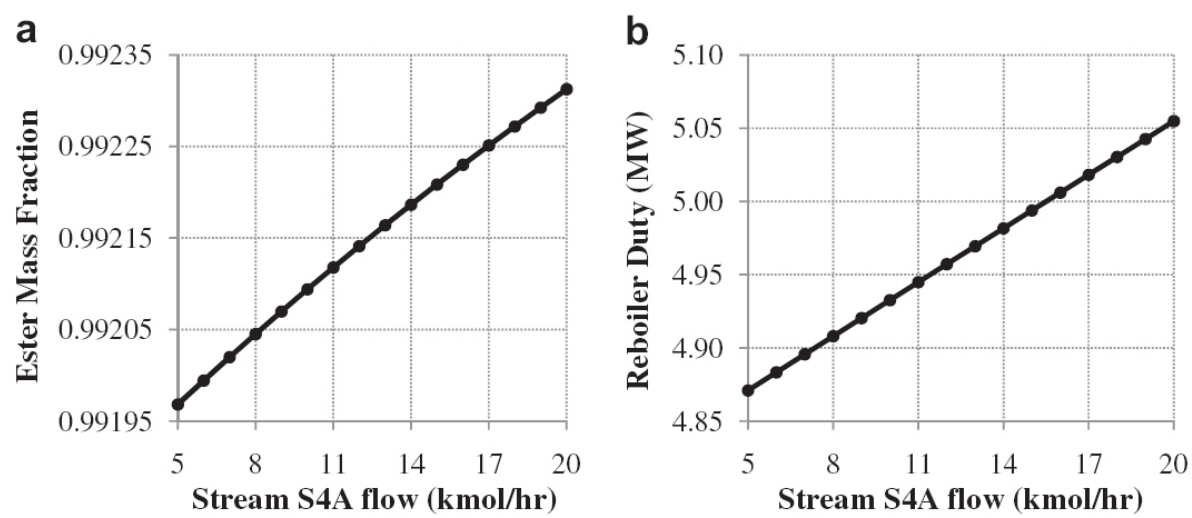

Figure 4. Sensitivity analysis of stream S4A flow rate on: (a) ester mass fraction in the bottom product stream; (b) column RD101 reboiler duty.

of UNIQUAC containing size and shape parameters is used to estimate the phase equilibrium because of the presence of the components with wide range of molecular weights within the column. The esterification reaction takes place in the reaction zone from stages 3-29 with solid acid catalyst of sulfated zirconia $\left(\mathrm{SO}_{4}^{-2} / \mathrm{ZrO}_{2}\right)$ [27-29]. Operation temperature of the catalyst ranging from 130 to $200^{\circ} \mathrm{C}$ and high activity even at high methanol/lauric acid ratio make it a suitable candidate for the RD application. The reverse hydrolysis reaction is negligible and the kinetic rate constant $\mathrm{s}$ is given by $k(T)=1.2 \times 10^{5}$ $\exp (-55,000 / R T)$ [12]. The units for reaction rate, concentration, and activation energy expressed as $\mathrm{kmol} /\left(\mathrm{m}^{3} \mathrm{~h}\right), \mathrm{kmol} /$ $\mathrm{m}^{3}$, and $\mathrm{kJ} / \mathrm{kmol}$, respectively. For each reaction stage, an estimated volume trichold up of $0.043 \mathrm{~m}^{3}$ is used [12]. The bottom separation zones, stage 30 , separates the desired product, methyl dodecanoate, while the top separation zone, stages 1 and 2 , removes the water and unreacted methanol.

\section{Biodiesel Plant}

A biodiesel production plant using reactive distillation sequence requires at least two columns for biodiesel separation and methanol recovery as seen in Figure 1a [13]. Figure $1 \mathrm{~b}$ proposes a thermally-coupled reactive distillation column sequence utilizing methanol and lauric acid (oil) to produce product methyl dodecanoate (biodiesel). Tables 1 and 2 summarize the stream properties for both the sequences. Stream LAURIC is preheated by stream ESTERB in heat exchanger HX101 to $100^{\circ} \mathrm{C}$ and enters to the top of the reaction zone at stage 3 of RD101. Stream METH combined with stream

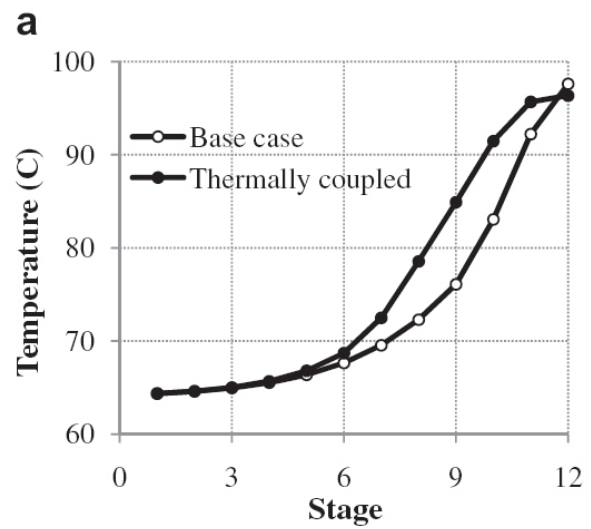

$\mathrm{S} 3 \mathrm{~B}$ in mixer M101 is preheated to $110^{\circ} \mathrm{C}$ in heat exchanger HX102 before it is fed to the bottom of the reaction zone at stage 29 of RD101. The feeds enter at the both ends of the reaction zone to maximize conversion [7,10-14]. Although the conversion nearly reaches completion in 23 reactive stages although, 27 stages are set for ensuring flexibility in the operation. Both feed streams are preheated to minimize the loss of exergy caused by the temperature gradient. The plant produces around $99.2 \mathrm{wt} \%$ of $21,527 \mathrm{~kg} / \mathrm{h}$ of methyl dodecanoate and dilute concentration of methanol in water as summarized in Tables 1 and 2 . The inlet streams conditions are identical while there is a slight difference of the product concentrations in the outlet streams between the two sequences of distillation columns.

The distillate, stream WATMET, of column RD101 is fed to stage 9 and 10 of column T101 of the BCRD and TCSRD sequences, respectively. Aspen Plus N Q curves (plots of heat load $Q$ versus total number of stages $N$ ) are used to determine the number of stages and optimum feed locations based on an objective function $[5,38]$. Column T101 recovers methanol from water and recycles. The column operates with 12 stages, with a kettle reboiler and a total condenser. The activity coefficient model of NRTL is used for predicting the equilibrium and liquid properties in column T101. The top product, stream S3A, containing mostly methanol is pressurized before it is recycled. The bottom product, stream WATA, is treated as a waste. Stream ESTERA and S3A are tear streams for both sequences, while stream S4A and WATMET are tear streams only for the TCSRD sequence.

b

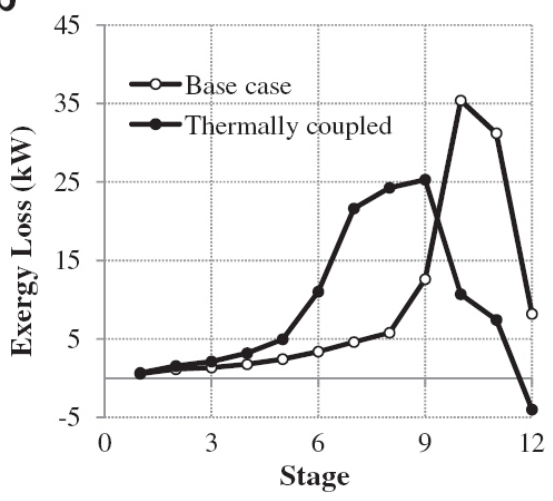

Figure 5. Comparison of operating conditions for distillation column T101: (a) temperature profiles; (b) exergy loss profiles. 
a

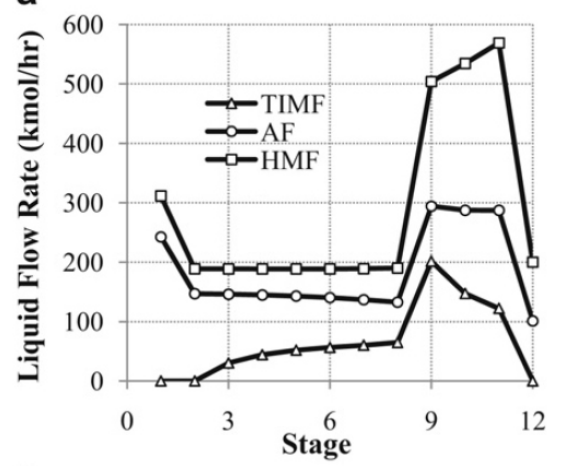

C

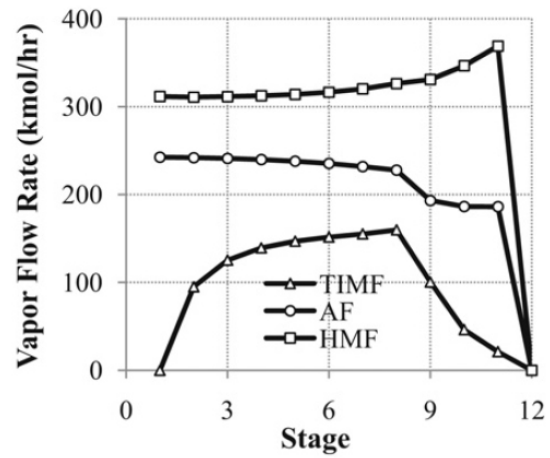

e

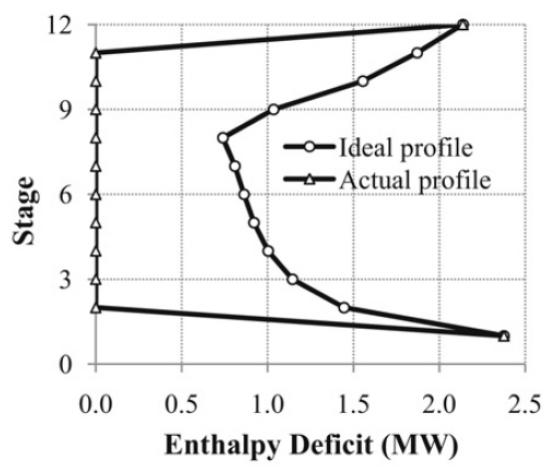

b

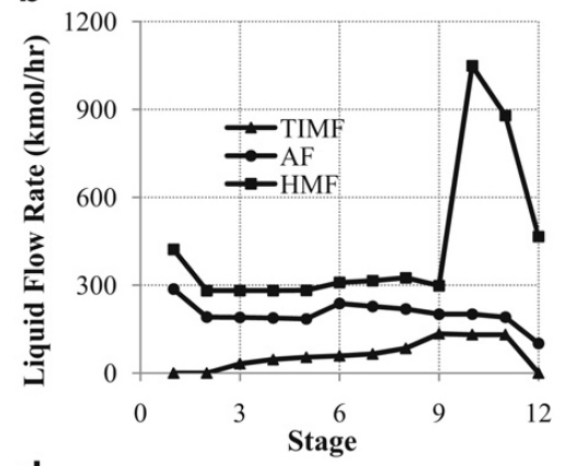

d

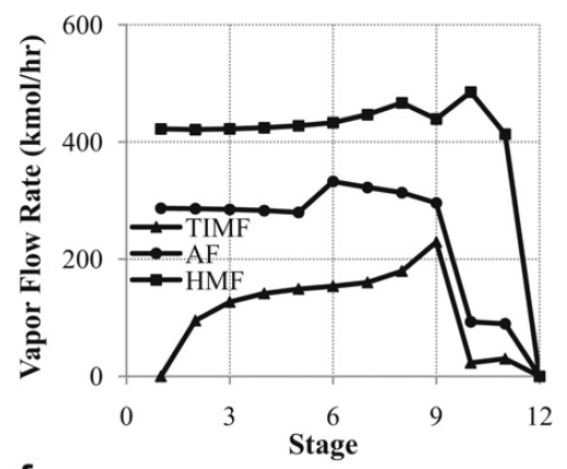

f

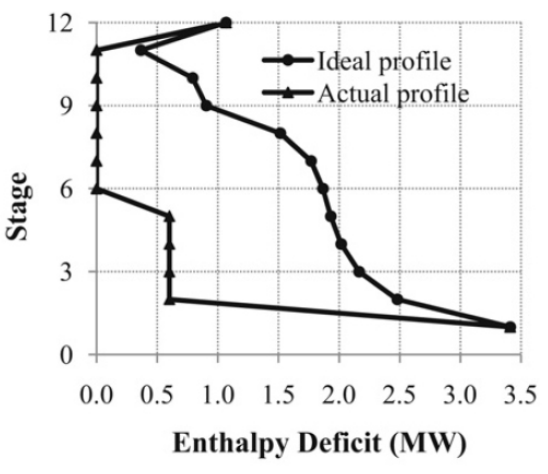

*TIMF-Thermodynamic ideal minimum flow; AF-Actual flow; HMF-Hydraulic maximum flow

Figure 6. Hydraulic analysis and enthalpy deficit profiles for column T101: (a) stage-liquid flow rate profiles of base case design; (b) stage-liquid flow rate profiles of thermally-coupled design; (c) stage-vapor flow rate profiles of base case design; (d) stage-vapor flow rate profiles of thermally-coupled design; (e) stage-enthalpy deficit curves of base case design; (f) stage-enthalpy deficit curves of the thermally-coupled design.

Table 4

Some of the streams properties for the base case and thermally coupled designs given in Figure 1.

\begin{tabular}{|c|c|c|c|c|c|c|c|c|}
\hline \multirow[b]{2}{*}{ Stream } & \multicolumn{4}{|c|}{ Base Case Design } & \multicolumn{4}{|c|}{ Thermally Coupled Design } \\
\hline & $\dot{n}_{(\mathrm{kmol} / \mathrm{h})}$ & $h(\mathrm{~kJ} / \mathrm{mol})$ & $s(\mathrm{~J} / \mathrm{mol}-\mathrm{K})$ & $E_{x}(\mathrm{~kW})$ & $\dot{n}_{(\mathrm{kmol} / \mathrm{h})}$ & $h(\mathrm{~kJ} / \mathrm{mol})$ & $s(\mathrm{~J} / \mathrm{mol}-\mathrm{K})$ & $E_{x}(\mathrm{~kW})$ \\
\hline S1 & 100 & -703.98 & -1255.47 & -9157.24 & 100 & -703.98 & -1255.47 & -9157.24 \\
\hline S2B & 200 & -228.82 & -212.87 & -9186.08 & 200 & -228.82 & -212.87 & -9186.08 \\
\hline ESTERA & 104 & -519.37 & -1012.14 & -6286.31 & 104 & -541.79 & -1050.46 & -6603.83 \\
\hline S4B & - & - & - & - & 25 & -278.11 & -152.94 & -1614.67 \\
\hline WATMET & 196 & -253.45 & -170.72 & -11027.47 & 221 & -217.43 & -82.96 & -11828.90 \\
\hline S4A & - & - & - & - & 25 & -278.77 & -154.61 & -1615.77 \\
\hline S3A & 95 & -234.69 & -226.71 & -4409.42 & 95 & -234.69 & -226.71 & -4409.42 \\
\hline WATA & 101 & -279.60 & -147.01 & -6614.73 & 101 & -280.37 & -149.25 & -6617.34 \\
\hline
\end{tabular}


Table 5

Minimum exergy of separation and thermodynamic efficiency estimations based on the converged simulation.

\begin{tabular}{|c|c|c|c|c|c|c|}
\hline \multirow[b]{2}{*}{ Column } & \multicolumn{3}{|c|}{ Base Case Design } & \multicolumn{3}{|c|}{ Thermally Coupled Design } \\
\hline & $\begin{array}{l}\dot{E}_{x_{\text {min }}} \\
(\mathrm{kW})\end{array}$ & $\begin{array}{l}\dot{E}_{x, \mathrm{los}} \\
(\mathrm{kW})\end{array}$ & $\eta$ & $\begin{array}{l}\dot{E}_{x \text { min }} \\
(\mathrm{kW})\end{array}$ & $\begin{array}{l}E_{x, \mathrm{los}} \\
(\mathrm{kW})\end{array}$ & $\begin{array}{l}\text { Saved } \dot{E}_{x} \\
(\mathrm{~kW})\end{array}$ \\
\hline RD101 & 1029.54 & 1189.04 & 0.46 & 1525.26 & 907.310 .63 & 281.73 \\
\hline T101 & 3.33 & 107.36 & 0.03 & -813.62 & 108.740 .88 & -0.38 \\
\hline Total & & 1297.40 & & & 1016.05 & 281.35 \\
\hline
\end{tabular}

\section{Results and Discussions}

\subsection{Column RD101}

Table 3 compares the operating conditions and configurations for reactive distillation column RD101 in base case and thermally-coupled sequences. The base case sequence operates with a total condenser, duty of $-2168.38 \mathrm{~kW}$, and a molar reflux ratio of 0.1 , while the thermally-coupled design has no condenser, and has the reboiler duty of $735.98 \mathrm{~kW}$ less than the base case sequence. However, higher pressure is required to achieve a comparable conversion due to the interconnecting vapor flow from the top of the column in thermally-coupled sequence. Interconnecting side stream S4B, with molar flow rate of $7 \mathrm{kmol} / \mathrm{h}$, cools down top of the column RD101 as seen in Figure 1b.

The temperature, composition, conversion, and exergy loss profiles in RD101 of both the sequences are shown in Figure 2. In the thermally-coupled column, the reaction zone temperature profile remains almost constant. The composition profiles (Figure $2 b$ ) indicate that the base case sequence contains higher water concentration in the reaction zone, which causes liquid-liquid separation leading to solid catalyst deactivation. Both sequences have comparable conversions as shown in Figure 2c. The exergy loss profiles, shown in Figure $2 \mathrm{~d}$, indicate that the exergy losses in the stages 4-28 for both reactive distillation columns overlap [38]. Exergy loss mainly occurs at the feed stages and in the reboilers. For column RD101, the total exergy loss of the thermally-coupled designis $23.7 \%$ less than the base case sequence. The hydraulic analyses shown in Figure 3a-d indicate that actual vapor and liquid flows overlap with the thermodynamic ideal minimum vapor and liquid flows, respectively, from stages 3-28. The hydraulic maximum flow (HMF) is higher for base case sequence for both actual liquid and vapor flows. No flooding or dried up stages have occurred. Figure $3 e$ and $f$ shows the stage-enthalpy CGCCs for the base case and thermally-coupled sequences produced by the thermal analysis; the ideal and actual profiles in the separation zones are close to each other.

\subsection{Column T101}

The base case and thermally-coupled distillation columns T101 operate with molar reflux ratios of 1.55 and 2.02, respectively, as shown in Table 2. Design specification is used to set the flow rate of water to $1 \mathrm{kmol} / \mathrm{h}$ in the distillate by varying the molar reflux ratio. The thermally-coupled column has a side withdrawal with a flow rate of $7 \mathrm{kmol} / \mathrm{h}$ at stage 10 , which is connected to the top stage of the reactive distillation column RD101. Both the reboiler duty and ester mass fraction in the bottom decrease as the flow rate of stream S4A is reduced as indicated in Figure 4 . The ester mass fraction is $99.2 \mathrm{wt} \%$ when stream S4A flow rate is $7 \mathrm{kmol} / \mathrm{h}$. Stream
S4A is pressurized by pump P102 to match the pressure in column RD101. The reboiler and condenser duties required for the base case sequence are $2136.23 \mathrm{~kW}$ and $-2375.23 \mathrm{~kW}$, respectively, while they are $1067.38 \mathrm{~kW}$ and $-3409.62 \mathrm{~kW}$, respectively, for the thermally-coupled sequence.

Figure 5 compares the temperature and exergy loss profiles for column T101.Hydraulic analysis (Figure 6a-d) shows that the actual liquid and vapor flow rates are between the TIMF (thermodynamic ideal minimum flow) and HMF. Stream WATMET is introduced at stages 9 and 10 of the base case and thermally-coupled sequences, respectively, to minimize the distortions due to inappropriate feed placement as shown in Figure 6e and $\mathrm{f}$. A significant area beneath the CGCC pinch point between the ideal and actual enthalpy profiles of the thermally-coupled column (Figure 6f) suggests the scope for side condensing. A side condenser with a heat duty of 600 $\mathrm{kW}$ is installed on stage 6 to reduce the area gap.

The stream properties and exergy values estimated by Equation (9) are shown in Table 4. Table 5 summarizes the total exergy lossess and thermodynamic efficiencies of the both sequences. The efficiency of column RD101 increases from $46 \%$ to $63 \%$, while the total exergy loss reduces by $281.35 \mathrm{~kW}$ in thermally-coupled sequence.

\section{Conclusions}

Thermally-coupled side-stripper reactive distillation sequence requires less energy and use one less condenser and hence results in lower capital investment and operating cost compared with the base case reactive distillation sequence. The thermally-coupled sequence reduces the energy consumption by $13.1 \%$ in the reactive distillation column and $50.0 \%$ in the methanol recovery column. In the thermallycoupled reactive distillation column, the content of water in the reaction zone is lower. This decreases liquid-liquid separation and protects solid catalyst from deactivation. The total exergy losses for the columns are reduced from 1297.40 $\mathrm{kW}$ to $1016.05 \mathrm{~kW}$ indicating a significant amount of available energy saving and operaton with less thermodynamic imperfections in thermally-coupled sequence.

\section{Nomenclature}

AF actual flow

CGCC column grand composite curve

BCRD base case reactive distillation

$\dot{D}$ distillate flow rate, $\mathrm{kmol} / \mathrm{h}$

$e_{x} \quad$ molar exergy, $\mathrm{kW} / \mathrm{kmol}$

$E_{x} \quad$ total Exergy, $\mathrm{kW}$

$h^{x} \quad$ enthalpy, $\mathrm{kJ} / \mathrm{kmol}$

$H \quad$ total enthalpy, $\mathrm{kJ}$

HMF hydraulic maximum flow

$\dot{L} \quad$ liquid flow rate, $\mathrm{kmol} / \mathrm{h}$

$\dot{m} \quad$ mass flow rate, $\mathrm{kg} / \mathrm{h}$

$\dot{n}$ molar flow rate, $\mathrm{kmol} / \mathrm{h}$

PNMTC practical near-minimum thermodynamic condition

$\dot{Q} \quad$ heat flow (heat transfer rate), $\mathrm{kW}$

$\dot{Q}_{C} \quad$ condenser duty, $\mathrm{kW}$

$\dot{Q}_{\mathrm{R}}^{\mathrm{C}} \quad$ reboiler duty, $\mathrm{kW}$

$R \quad$ reflux ratio, universal gas constant 
RD reactive distillation

$s$ molar entropy, $\mathrm{kJ} / \mathrm{kmol} \mathrm{K}$

$T$ temperature, $\mathrm{K}$

TA thermodynamic analysis

TCRD thermally-coupled reactive distillation

TIMF thermodynamic ideal minimum flow

$x \quad$ liquid mole fraction

y vapor mole faction

$V \quad$ vapor flow rate, $\mathrm{kmol} / \mathrm{h}$

W work, $\mathrm{kW}$

Greek symbols

$\eta \quad$ efficiency

$\lambda$ heat of vaporization, $\mathrm{J} / \mathrm{mol}$

\section{Subscripts}

C condenser

D distillate

def deficit

F feed

V vapor

$\mathrm{H}$ heavy

L light

min minimum

$\mathrm{R} \quad$ reboiler

s stream, shaft

* equilibrium condition

o reference state

\section{References}

[1] Khalifa M, Emtir M. Rigorous optimization of heat-integrated and Petlyuk column distillation configurations based on feed conditions. Clean Technol Environ Policy 2009; 11: 107-13.[2] Demirel Y. Retrofit of distillation columns by thermodynamic analysis. Sep Sci Technol 2006; 41: 791-817.

[3] Nakaiwa M, Huang K, Owa M, Akiya T, Sato M, Takamatsu T. Energy savings in heat-integrated distillation columns. Energy 1997; 22: 6,210-5.

[4] Demirel Y. Thermodynamic analysis of separation systems. Sep Sci Technol 2004; 39: 3,897-942.

[5] Nguyen N, Demirel Y. Retrofit of distillation columns in biodiesel production plants. Energy 2010; 35: 1,625-32.

[6] Demirel Y. Assessment of thermodynamic performances for distillation columns. Int J Exergy 2006; 3: 345-61.

[7] Nguyen N, Demirel Y. Reactive distillation column esterification of lauric with methanol: equilibrium vs. nonequilibrium approaches; 2010. AIChE Annual Meeting; 2010 Nov 7-12, Salt Lake City, Utah.

[8] Araújo AB, Brito RP, Vasconcelos LS. Exergetic analysis of distillation processeses a case study. Energy 2007; 32: 1,185-93.

[9] Kiss AA, Pragt JJ, van Strien CJG. Reactive dividing-wall columns-defying equilibrium restrictions. Chem Prod Process Model 2009; 4. Article 2.

[10] Omota F, Dimian AC, Bliek A. Fatty acid esterification by reactive distillation. Part 1: equilibrium-based design. Chem Eng Sci 2003; 98: 3,159-74.

[11] Omota F, Dimian AC, Bliek A. Fatty acid esterification by reactive distillation. Part 2: kinetics-based design for sulphated zirconia catalysts. Chem Eng Sci 2003; 58: 3,175-85.

[12] Dimian AC, Bildea CS, Omota F, Kiss AA. Innovative process for fatty acid esters by dual reactive distillation. Comput Chem Eng 2009; 33: 743-50.

[13] Kiss AA, Dimian AC, Rothenberg G. Biodiesel by catalytic reactive distillation powered by metal oxides. Energy Fuels 2008; 22: 598-604.
[14] William L, Cheng-Ching Y. Reactive Distillation Design and Control. New York: Wiley; 2008.

[15] Malinen I, Tanskanen J. Thermally-coupled side-column configurations enabling distillation boundary crossing. 1. An overview and solving procedure. Ind Eng Chem Res 2009; 48: 6,387-404.

[16] Malinen I, Tanskanen J. Thermally-coupledside-column configurations enabling distillation boundary crossing. 2. Effects of intermediate heat exchangers. Ind Eng Chem Res 2009; 48: 6,372-86.

[17] Rong B-G, Kraslawski A, Turunen I. Synthesis of heat-integrated thermally-coupled distillation systems for multicomponent separations. Ind Eng Chem Res 2003; 42: 4,329-39.

[18] Rong B-G, Turunen I. Synthesis of new distillation systems by simultaneous thermal coupling and heat integration. Ind Eng Chem Res 2006; 45: 3,830-42.

[19] Agrawal R, Fidkowski Z. Are thermally-coupled distillation columns always thermodynamically more efficient for ternary distillations? Ind Eng Chem Res 1998; 37: 3,444-54.

[20] Asprion N, Kaibel G. Dividing wall columns: fundamentals and recent advances. Chem Eng Process Process Intensif 2010; 49: 139-46.

[21] Wang S-J, Lee H-Y, Ho J-H. Plantwide design of ideal reactive distillation processes with thermal coupling. Ind Eng Chem Res 2010; 49: 3,262-74.

[22] Gomez-Castro FI, Rico-Ramirez V, Segovia-Hernandez JG, Hernandez S. Feasibility study of a thermally-coupled reactive distillation process for biodiesel production. Chem Eng Process Process Intensif 2010; 49: 262-9.

[23] Errico M, Rong B-G, Tola G. Process intensification for the retrofit of a multi-component distillation plant -an industrial case study. Ind Eng Chem Res 2008; 47: 1,975-80.

[24] Petlyuk FB. Distillation Theory and Its Application to Optimal Design of Separation Units. Cambridge, U.K.: Cambridge; 2004.

[25] Hernandez S, Segovia-Hernandez JG, Rico-Ramirez V. Themodynamically equivalent distillation schemes to the Petlyuk column for ternary mixtures. Energy 2006; 31: 2,167-83.

[26] Barroso-Muñoz FO, Hernández S, Segovia-Hernández JG, Hernández-Escoto H, Aguilera-Alvarado AF. Thermally-coupled distillation systems: study of an energy-efficient reactive case. Chem Bio Eng 2007; 2: 115-20.

[27] Kansedo JB. Synthesis of biodiesel from palm oil and seamango oil using sulfated zirconia catalyst (Thesis). Malaysia: Universiti Sains Malaysia; 2009.

[28] Garcia CM, Teixeira S, Marciniuk LL, Schuchardt U. Transesterification of soybean oil catalyzed by sulfated zirconia. Bioresour Technol 2008; 99: 6,608-13.

[29] Kiss AA, Dimian AC, Rothenberg. Solid acid catalysts for biodiesel production-towards sustainable energy. Adv Synth Catal 2006; 348: 75-81.

[30] Agrawal R, Herron DM. Efficient use of an intermediate reboiler and condenser in a binary distillation. AIChE J 1998; 44: 1,303-15.

[31] Rivero R. Exergy simulation and optimization of adiabatic and diabatic binary distillation. Energy 2001; 26: 561-93.

[32] DeKoeijer GM, Rivero R. Entropy production and exergy loss in experimental distillation columns. Chem Eng Sci 2003; 58: 1,587-97.

[33] Suphanit B, Bischert A, Narataruksa P. Exergy loss analysis of heat transfer across the wall of the dividing-wall distillation column. Energy 2007; 32: 2,121-34.

[34] Bandyopadhyay S, Malik RK, Shenoy UV. Temperature-enthalpy curve for energy targeting of distillation columns. Comput Chem Eng 1998; 22: 1,733-44.

[35] Dhole VR, Linnhoff B. Distillation column targets. Comput Chem Eng 1993; 17: 549-60.

[36] Chang H, Li Jr W. A new exergy method for process analysis and optimization. Chem Eng Sci 2005; 60: 2,771-84.

[37] Bandyopadhyay S. Effect of feed on optimal thermodynamic performance of a distillation column. Chem Eng J 2002; 88: 175-86.

[38] Aspen Engineering Suite, www.aspentech.com; 2004.

[39] Demirel Y. NonequilibriumTthermodynamics Transport and Rate Processes in Physical, Chemical and Biological Processes. $2^{\text {nd }}$ ed. Amsterdam: Elsevier; 2007. 